\title{
Renal Tuberculosis
}

National Cancer Institute

\section{Source}

National Cancer Institute. Renal Tuberculosis. NCI Thesaurus. Code C123020.

Infection of the kidney due to mycobacteria. 